\title{
AFRICAN MONSOON MULTIDISCIPLINARY ANALYSIS An International Research Project and Field Campaign
}

\author{
by Jean-Luc Redelsperger, Chris D. Thorncroft, Arona Diedhiou, \\ Thierry Lebel, Douglas J. Parker, and Jan Polcher
}

\begin{abstract}
AMMA strives to improve our understanding of the West African Monsoon system and will facilitate the multidisciplinary analysis needed to improve prediction of its variability and its associated societal impacts.
\end{abstract}

AFFILIATIONS: ReDELSPERGER-CNRM/GAME CNRS and MeteoFrance, Toulouse, France; THORNCROFT-State University of New York at Albany, Albany, New York; Diedhiou AND LebeL-LTHE, IRD, Niamey, Niger; PARKER - University of Leeds, Leeds, United Kingdom; POLCHER - LMD, CNRS, Paris, France

CORRESPONDING AUTHOR: Chris Thorncroft, Department of Earth and Atmospheric Sciences, University at Albany, SUNY, Albany, NY 12222

E-mail: chris@atmos.albany.edu

The abstract for this article can be found in this issue, following the table of contents.

DOI:10.1175/BAMS-87-12-1739

In final form 7 July 2006

(C)2006 American Meteorological Society decades as demands on resources increase in association with one of the world's most rapidly growing populations. Vulnerability may be further increased in association with the effects of climate change and other factors linked to the fast-growing population, such as land degradation and water pollution.

Recognizing the societal need to develop strategies that reduce the socioeconomic impacts of the variability of the WAM, AMMA will facilitate the multidisciplinary research required to provide improved predictions of the WAM and its impacts. The international AMMA project has three overarching aims:

1) To improve our understanding of the WAM and its influence on the physical, chemical and biological environment regionally and globally;

2) To provide the underpinning science that relates variability of the WAM to issues of health, water resources, food security and demography for West African nations and defining and implementing relevant monitoring and prediction strategies; and

3) To ensure that the multidisciplinary research carried out in AMMA is effectively integrated with prediction and decision making activity. 
AMMA is endorsed by the World Climate Research Programme (WCRP) and continues to develop in association with the Climate Variability and Predictability (CLIVAR) and Global Energy and Water Cycle Experiment (GEWEX). AMMA has also been endorsed by two projects within the International Geosphere-Biosphere Programme (IGBP): International Global Atmospheric Chemistry (IGAC) and Integrated Land Ecosystem-Atmosphere Processes Study (ILEAPS). AMMA is working with other international projects and programs to achieve its aims, including the Global Climate Observing System (GCOS), Global Ocean Observing System (GOOS), and The Observing System Research and Predictability Experiment (THORPEX).

MOTIVATION AND MAJOR ISSUES. The interannual and interdecadal variability of WAM is well documented and has motivated considerable research efforts (e.g., Nicholson 1981; Lamb 1983; Folland et al. 1986; Fontaine and Janicot 1996; Le Barbé et al. 2002). The dramatic change from wet conditions in the 1950s and 1960s to much drier conditions in the 1970 s, 1980s, and 1990s over the whole region represents one of the strongest interdecadal signals on the planet in the twentieth century. Superimposed on this, marked interannual variations in recent decades have resulted in extremely dry years with devastating environmental and socioeconomic impacts. Such variability has raised important issues related to

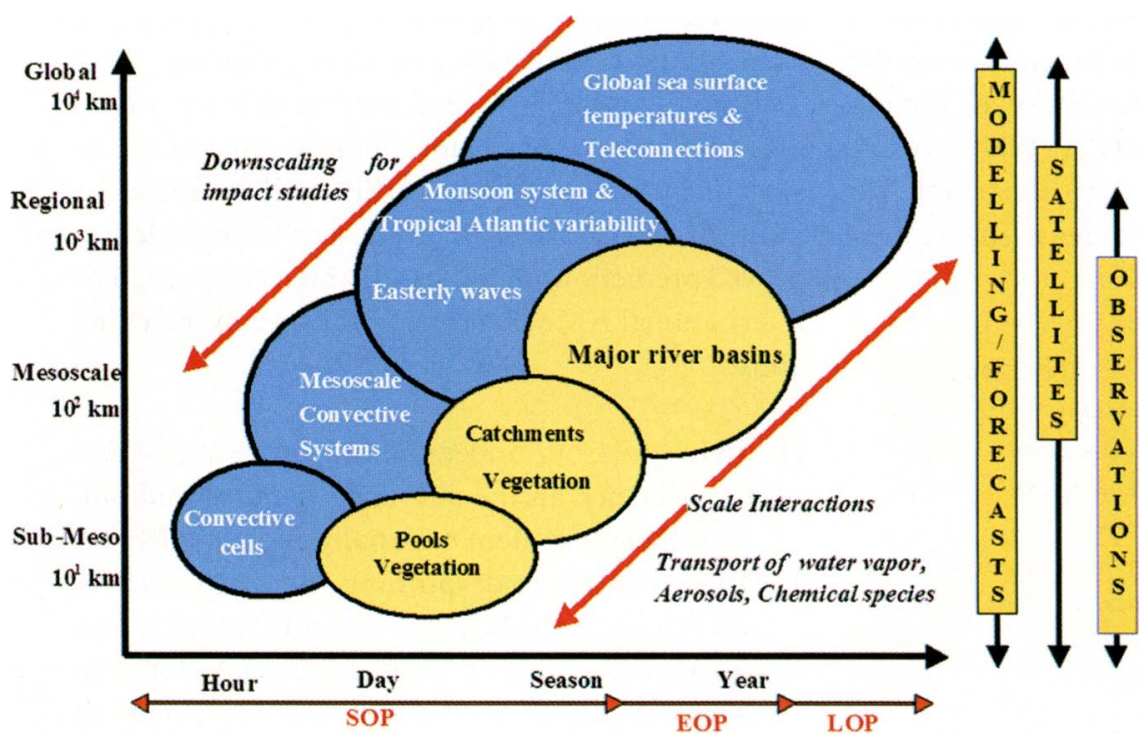

FIG. I. Simplified schematic of key phenomena together with their associated space and time scales. The arrow is included to highlight the importance of scale interactions and transport processes in the WAM. SOP, EOP and LOP refer to the AMMA observing periods, Special Observing Period, Enhanced Observing Period and Long-term Observing Period respectively. sustainability, land degradation, and food and water security in the region.

We are currently hindered in providing skillful predictions of WAM variability and its impacts. There are still fundamental gaps in our knowledge of the coupled atmosphere-land-ocean system at least partly arising from a lack of appropriate observational datasets, but also because of the complex scale interactions between the atmosphere, biosphere, and hydrosphere, which ultimately determine the nature of the WAM. The monitoring system for WAM and its variability are inadequate, with many gaps in the standard routine network and a lack of routine monitoring of some key variables. While the next generation of satellites will undoubtedly help with routine monitoring and prediction efforts, more research is required to validate and exploit these data streams. Dynamical models used for prediction suffer from large systematic errors in the West African and tropical Atlantic regions (e.g., WCRP 2000; Davey et al. 2002). Finally, there is a lack of integrative science linking the work on WAM variability with work on food, water, and health impacts.

The WAM system provides an ideal framework for considering scale interactions in a monsoon system: it possesses pronounced zonal symmetry with characteristic jets and associated well-defined weather systems. Research on such scale interactions, and in particular those linking dynamics and convection with the land surface, will be relevant to other monsoon systems and is needed in order to improve the coupled atmosphere-ocean-land models used for weather and climate prediction. In order to carry out this research extra observations are needed.

Further motivation for a research project concerned with WAM variability and predictability comes from recognizing the role West African weather and climate has on the rest of the world. Latent heat release in deep cumulonimbus clouds in the ITCZ over Africa represents one of the major heat sources on the planet. Its meridional migration and associated 
regional circulation impact other tropical and midlatitude regions, as exemplified in the known correlation between West African rainfall and Atlantic hurricane frequency (e.g., Landsea and Gray 1992). In addition to the large-scale interactions, we know that a majority of hurricanes that form in the Atlantic originate from weather systems over West Africa (e.g., Avila and Pasch 1992); however, we know little about the processes that influence this and why only a small fraction of these "seedlings" actually become hurricanes. Tropical Africa is also the world's largest source of atmospheric dust. Both the fire aerosols and dust play a major role in radiative forcing and in cloud microphysics, and thus are an important part of the WAM system that require study.

Finally, West Africa is also an important source region for natural and anthropogenic emissions of precursors to key greenhouse forcing agents (e.g., ozone, aerosols). For example, Africa contributes around $20 \%$ to the global biomass-burning fires. Long-range transport of trace gases out of West Africa has important implications for the global oxidizing capacity of the atmosphere (which controls the level of many greenhouse gases), global climate change, and the transport of key constituents (e.g., water vapor, ozone-depleting substances) into the stratosphere.

A review of the present state of knowledge on the West African monsoon and the related scientific questions to be addressed by AMMA are described in the International Science Plan (ISP). The ISP also includes a description of the strategy proposed to tackle these questions. The ISP is available on the international AMMA Web site (online at www. amma-international.org/science/docs/AMMA_ISP_ May2005.pdf).

THE AMMA PROGRAMME. A multiscale approach. To address the multiple scales that characterize WAM, the AMMA program is structured around the following four interacting spatial scales (Fig. 1): i) global scale: the scale at which WAM interacts with the rest of the globe (Emphasis is given to improving our understanding of the role of global SST patterns on WAM variability; seasonalto-decadal variability is the main time scale of interest.); ii) regional scale: the scale at which we consider monsoon processes and scale interactions [Emphasis is given to improving our understanding of the interactions between the atmosphere, land, and tropical Atlantic ocean (especially the Gulf of Guinea). It is important to study the role of landsurface feedbacks on variability of the WAM at this scale, including the key roles of vegetation and soil moisture. The annual cycle and seasonal-to-interannual variability are the main time scales of interest.]; iii) mesoscale: the scale of the typical rain-producing weather systems [This scale is central to the understanding of scale interactions in the WAM system (e.g., through interactions with synoptic easterly waves and the African easterly jet), and the coupling between hydrology and the atmosphere at the catchment scale.]; iv) local or submesoscale: from an atmospheric point of view, this is the convective rain scale (It is central to the hydrology of the Sahel and of small watersheds to the south; it is the main scale of interest for agriculture and for human impact studies in general).

AMMA emphasizes the importance of an improved understanding of how these scales interact and combine to characterize the WAM and its variability, including how these interactions impact the sources and transport of water vapor, aerosol, and key chemical species (e.g., key greenhouse gases, ozone, and aerosol precursors) in the West African region and globally.

Integrative science. While it is convenient and appropriate to describe the research plans in terms of the different spatial scales for an improved understanding, it is essential to study the scale and process interactions. The implementation of AMMA is designed in this spirit (Fig. 2). The AMMA project integrates the scales at which the geophysical and human processes interact. Furthermore, the various disciplines involved in the study of WAM need to be integrated to achieve the three overarching aims. This approach has guided the structuring of the scientific objectives.

From the geophysical perspective, the fundamental science underpinning the AMMA project can be viewed as the various disciplines coming together within broader integrative science topics: i) the interactions between WAM and global climate from a physical as well as a chemical perspective, ii) the water cycle of WAM from the regional to the local scale, and iii) the coupled atmosphere-land-ocean system and its multiple scales. To feed these integrative topics with sound disciplinary knowledge of the processes and their scale dependence detailed studies of the following processes are needed: i) atmospheric processes, with a focus on the convective processes that are key to the rainfall production; ii) oceanic processes, because they contribute to and depend on WAM; iii) biophysical processes over the continent from the regional to the local scale; and iv) aerosol and chemical processes in the atmosphere. 


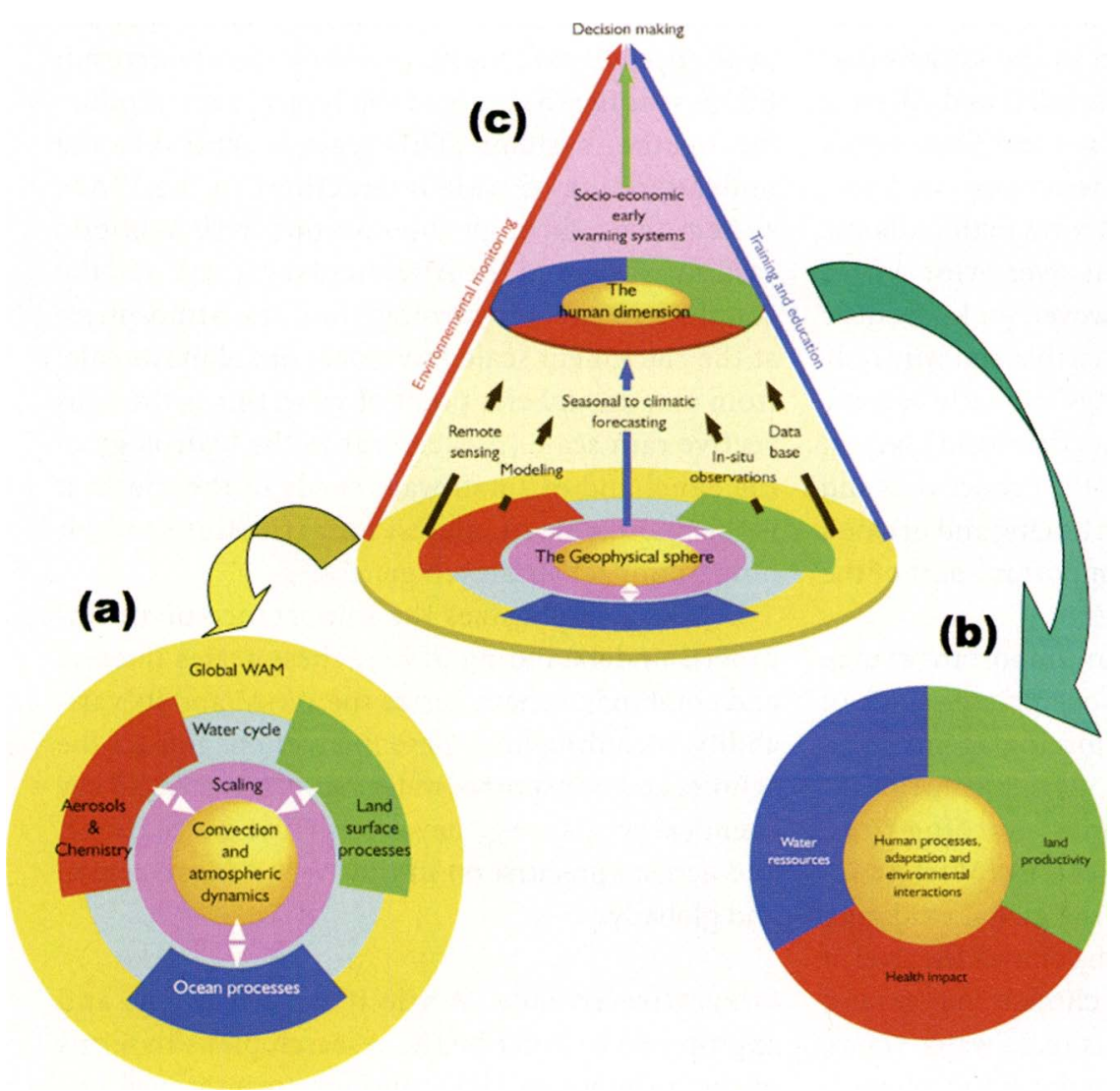

FIG. 2. Implementation of AMMA: (a) Integrative science for the geophysical and (b) human dimension. (c) Integration from this knowledge through various tools and for the exploitation by impact studies.

To study the human dimension of the variability and possible trends in the West African monsoon, AMMA aims to address the direct impact of the environmental conditions on the following three limiting conditions for African societies: i) land productivity, ii) water resources, and iii) health impacts. This activity will be coordinated to achieve a better understanding of how weather and climate variability impact food security and human processes in the region.

To achieve the AMMA scientific objectives and master the challenge of multiscale and multidisciplinary aspects, the following consistent set of tools and methods adapted to the problem of the West African monsoon will be used: i) models and data assimilation; ii) field campaigns; iii) satellite remote sensing and long-term atmosphere, and ocean data collection; and iv) database creation. These activities are key to transferring knowledge from the geophysical community in AMMA to the activities in the human dimension. AMMA will strive to use the above tools and activities to collect and consolidate knowledge, integrate the knowledge, and materialize the predictive skill gained with this knowledge.

The field program. AMMA is a multiyear project and involves three nested observation periods. The enhancement of observations during these periods will provide a unique opportunity to determine the future operational monitoring necessary to improve weather and climate forecasts over the West African region. More than this, a high priority for AMMA is to establish this operational network of observations, providing a visible legacy useful for society from the international AMMA program.

- The Long term Observing Period (LOP) is concerned with observations of two types: (i) historical observations to study interannual-to-decadal variability of the WAM (including currently unarchived observations) and (ii) additional long term observations (2002-2010) to document and analyse the interannual variability of the WAM.

- The Enhanced Observing Period (EOP) is designed to serve as a link between the LOP and the SOP (below). Its main objective is to document over a climatic transect the annual cycle of the surface conditions and atmosphere and to study the surface memory effects at the seasonal scale. The EOP will be 2-3 year duration (2005-2007).

- The Special Observing Period (SOP) focused on detailed observations of specific processes and weather systems at various key stages of the rainy season during three periods in the summer of 2006: (i) the dry season (Jan-Feb), (ii) Monsoon onset (15 May-30 June), (iii) Peak monsoon (1 July14 August) and (iv) Late monsoon (15 August15 September).

More detailed information regarding the different field phases, including this year's special observing period (SOP), is available in the ISP and in the 
AMMA implementation (see the AMMA Web site online at www.amma-international.org). Here we only briefly describe the different periods.

Central to the observing strategy for AMMA is the Coupling of the Tropical Atmosphere and the Hydrological Cycle (CATCH) hydrology project. $\mathrm{CATCH}$ has established enhanced observations in the "CATCH window" depicted in Fig. 3 to support the long-term monitoring of the surface component of the continental water cycle. It includes three mesosites that sample different environments along a climate transect. The observing strategy for the EOP is to enhance the observations of the atmosphere, land, and ocean along the "climate transect," which includes the CATCH hydrology project. These enhancements include i) extra radiosoundings, ii) new surface flux measurements along the climate transect, iii) ground-based remotely sensed observations (e.g., radars, profilers), iv) enhanced hydrological observations (underground water fluxes, soil moisture), and vegetation, aerosol, and trace gas monitoring, and v) ocean observations in the tropical Atlantic, including the Gulf of Guinea, to extend the climate transect into the ocean key for understanding the coupled WAM system.

Embedded within the multiyear framework provided by the long-term observing period (LOP)/ EOP is the SOP. Detailed studies of key processes, impractical to study in a multiyear framework, will be carried out within the SOP and are focused on enhancing the observations along the climate transect through the provision of additional ground-based instruments (e.g., radars, lidars, sodars, high-frequency radiosoundings, etc.), research aircraft, and other platforms (e.g., driftsonde, tethered balloons, etc.). A considerable effort was made to ensure that all relevant data (e.g., extra radiosondes, dropsondes) were broadcast to the Global Telecommunication System (GTS) to support operational forecasting and to facilitate future observing system experiments (see working group 5 below). The special measurements proposed during the SOP, combined with those established through the LOP/EOP, will provide the international community with an invaluable set of observations to investigate the multiple-scale interactions and processes that determine the nature of WAM and its variability.

Modeling studies in AMMA. AMMA will coordinate various modeling activities and will ensure that the benefits of this work are communicated to the operational prediction centers. The datasets obtained in AMMA provide a unique opportunity to assess the ability of models to predict WAM and its impacts at daily-tointerannual time scales, to evaluate and improve key parameterizations, and to recommend a sustained

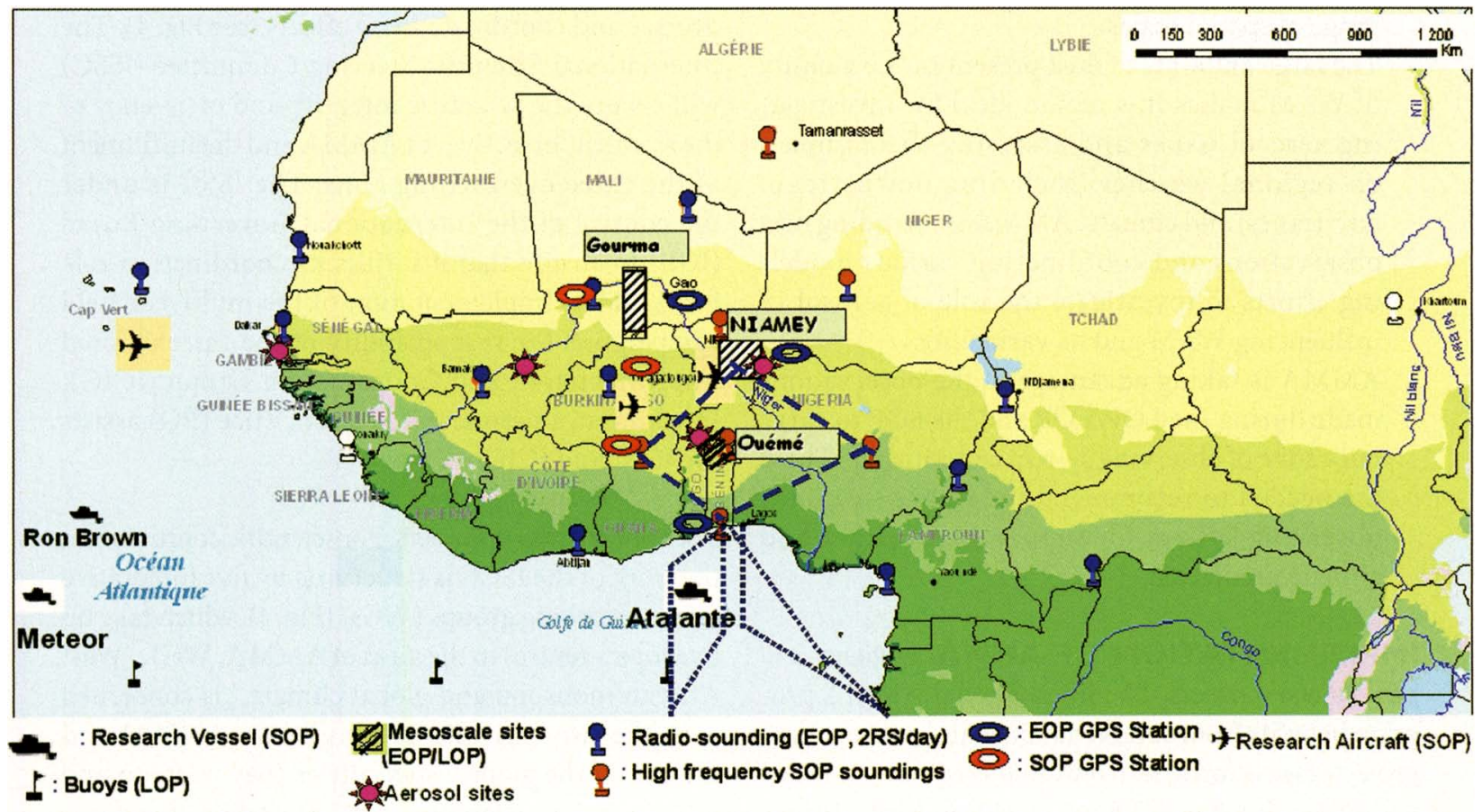

FıG. 3. Field implementation of AMMA observations based on nested networks. Circles indicated the atmospheric sounding network activated during the SOP. 
observing system necessary for further research and prediction at these time scales. The following are several foci for modeling studies in AMMA:

- State-of-the-art general circulation models (GCMs) used for weather and climate prediction have difficulty simulating the annual cycle of rainfall and associated regional circulations. AMMA observations along the climate transect, including the extension into the ocean, will be especially useful for exploring the interactions between the heat low and the ITCZ and investigating how well these are represented in dynamical models.

- The zonal symmetry of the low-level thermodynamic contrasts, well-defined jets, and associated weather systems make this an ideal natural laboratory for investigating scale interaction issues in monsoon systems (Redelsperger et al. 2002). Together with analysis of the intense diurnal cycle (see Parker et al. 2005), such investigations are central for improving the GCMs used for weather and climate prediction in West Africa and tropical Atlantic regions.

- Recent modeling studies (e.g., Koster et al. 2004) suggest that land surface-atmosphere feedbacks are particularly strong in the West African region. However, observations are currently lacking in order to evaluate these studies. AMMA will provide new observations to explore land surface-atmosphere interactions and associated feedbacks, including how these are modeled at a range of spatial scales.

- The large amounts of dust present in the vicinity of WAM makes this region ideal for investigating aerosol issues and assessing their impact on regional weather (including downstream hurricanes) and climate. AMMA is providing new observations and coordinating various modeling efforts to investigate the role of aerosol in influencing WAM and its variability.

- AMMA is taking advantage of the observations made during the LOP/EOP and the SOP to carry out a suite of observing system experiments. These are needed to recommend the future sustained observing system for supporting weather and climate prediction.

IMPLEMENTATION OF AMMA. National and pan-national projects. The international AMMA program benefits from several national and pan-national projects (see information online at www.amma-international.org/projects/index). AMMA-Africa brings together scientists from many African nations and coordinates their contribution to AMMA. It is based on proposals made by teams in universities and operational and research centers. Compared to the other components of AMMA, the emphasis in AMMA-Africa is more on impact studies. AMMA-EU is an integrated project funded by the European Union. It federates most of the national activities in Europe and brings together the geophysical and socioeconomic communities working in Africa. AMMA-France, which initiated AMMA, is a project supported by all French research organizations involved in environmental sciences and covers most aspects of AMMA. AMMA-UK is the sum of various projects associated with a Natural Environmental Research Council (NERC)-funded consortium, bringing together the British AMMA community. AMMA-US gathered a number of American scientists to prepare a U.S. proposal for AMMA. While this was not supported as a unified program, the Department of Energy (DOE), National Aeronautics and Space Administration (NASA), and National Oceanic and Atmospheric Administration (NOAA) are supporting several projects that incorporate some subprojects that arose from this proposal.

International coordination. AMMA aims to strengthen the international framework needed to facilitate interactions between researchers working in the different national and pan-national projects and to ensure that the field campaigns are well coordinated to optimize the scientific impact of the observations. An international structure has been established to oversee and coordinate these efforts (see Fig. 4). The International Scientific Steering Committee (ISSC) will ensure the scientific integrity and coherency of the scientific objectives of AMMA and the fulfillment of the three overarching aims. The ISSC is under the control of the International Governing Board (IGB) to ensure that it fulfills its coordination role for AMMA. Implementation of the multiyear field campaign is the responsibility of the International Implementation and Coordination Group (ICIG). In addition, a permanent Project Office (PO) assists the ISSC and ICIG.

SCIENTIFIC Working Groups. For scientific coordination the work of the ISCC is structured by five integrative science working groups (WGs) (Fig. 4), which take up five topics central to the aims of AMMA. WG1, "West African monsoon and global climate," is concerned with the two-way interactions between WAM and the rest of the globe, especially as they relate to and influence the variability of WAM and its global impacts. It includes aerosol and chemistry aspects. WG2, "Water cycle," is concerned with the processes in- 
volved in the water budget occurring through all scales (i.e., regional scale, mesoscale, and local scale; see Fig. 1). WG3, "Surfaceatmosphere feedbacks," is concerned with providing increased knowledge and understanding of the coupling between atmosphere and continental surfaces at the regional scale and mesoscale and, separately, the coupling between the atmosphere and ocean (the coupled atmosphere-landocean system is addressed in WG1). WG4, "Prediction of climate impacts," is concerned with the second major aim of AMMA and will provide strong linkages between the work taking place on impacts and that taking place on observed variability and predictability of WAM in WG1. WG5, "High-impact weather prediction and predictability," is a joint WG with THORPEX and is concerned with improving our knowledge and understanding of high-impact weather over the West African continent, and its impacts on the tropical Atlantic and extratropics. Operational activities will be promoted, including the tailoring of forecast products for users, and data impact and targeting studies.

IMPLEMENTATION OF FIELD OBSERVATIONS. The implementation of the field program is carried out through the establishment of task teams (TTs) and support teams (STs). The TT responsibilities are i) to design an observational strategy for a given subset of scales/variables of interest that addresses the scientific objectives presented in the ISP, and ii) to monitor and have final responsibility for deployment of relevant instrumentation. The TTs are composed of the Principal Investigators (PIs) of the instruments planned to be deployed in the framework of the space/time scale covered by the TTs. The SST responsibilities are i) to act in support of TTs, ii) to look in more detail into operational matters, and iii) to propose a scheme of operations to be agreed upon by TT leaders and to be submitted to the ISSC to verify that these schemes satisfy the needs of AMMA.

The AMMA Operations Centre (managed by ST2) was particularly important for facilitating the

smooth running of the field program during the SOP. A crucial component of this was the forecasting activity to support in-the-field decision making. The AMMA forecasting team represented a successful collaboration between numerical weather prediction centers [the European Centre for Medium-Range Weather Forecasts (ECMWF), Météo-France, National Centers for Environmental Prediction (NCEP), and the Met Office], together with the African Centre of Meteorological Application for Development (ACMAD) and African Weather Services. The AMMA forecasting team was responsible for the development of a comprehensive set of Web pages to support forecasting in the West African region (see information online at http://aoc.amma-international.org), which will be maintained as far as possible after the SOP to support future operational forecasting. AMMA is also establishing several training activities for African forecasters, including coordinating visits to ECMWF and NCEP (Africa desk) and also a series of training workshops in collaboration with ACMAD in Niamey, Niger. The aim of these workshops is to discuss forecasting strategies and to help familiarize forecasters with new forecasting products (before the SOP), and to evaluate these products and debrief the forecasting activity (after the SOP).

FINAL COMMENTS. AMMA has been carefully conceived to improve our fundamental understanding of the West African monsoon and its societal impacts, 
and to make sustainable improvements to monitoring and predicting the West African environment. Our activities are embedded within a "long-term observing period" ("LOP") structure, which will ensure that our intensive activities are directed toward systematic improvements in monitoring and predicting over the coming decades. We will develop and upgrade two important land-based atmospheric monitoring systems (for the upper-air and surface fluxes), and over the LOP we will transfer responsibility for these networks to the local African agencies. In addition, ocean-monitoring systems in the tropical Atlantic, including the Gulf of Guinea, that have been shown to improve both weather and climate forecasts will continue to provide data to these groups. These networks of observations are of enormous value both to global prediction systems and to local forecasting systems based in Africa.

ACKNOWLEDGMENTS. Based on an French initiative, AMMA was built by an international scientific group and is currently funded by a large number of agencies, especially from France, the United Kingdom, the United States, and Africa. It has been the beneficiary of a major financial contribution from the European Community's Sixth Framework Research Programme. Detailed information on scientific coordination and funding is available on the AMMA International Web site at www.amma-international.org.

AMMA relies on the inputs and help of many people. We would also like to give special thanks to the members of the AMMA Project Office: Elisabeth van der Akker, Isabelle Genau, Karine Ginoux, and Cheikh Kane. We would like to acknowledge all other members of the International Scientific Steering Committee: Ernest Afiesimama, Abel Afouda, Abou Amani, Anton Beljaars, Benrard Bourles, Andreas Fink, Amadou Gaye, Jim Haywood, Paul Houser, Peter Lamb, Bob Molinari, Joe Prospero, Claire Reeves, and Madeleine Thomson. We would like to thank also other people helping to lead WGs, TTs, and STs, especially Peter Brandt, Bernard Cappelaere, Lassine Dairra, Luc Descroix, Laurence Eymard, Michel Desbois, Cyrille Flamant, Laurence Fleury, Sylvie Galle, Serge Janicot, Greg Jenkins, Sarah Jones, Jean-Phlippe Lafore, Colin Lloyd, Celine Mari, Béatrice Marticorena, Andy Morse, Eric Mougin, Jacques Pelon, Alain Protat, Christophe Peugeot, Florence Rabier,
Frank Roux, Paulo Ruti, Josiane Seghieri, Chris Taylor, and Zoltan Toth.

\section{REFERENCES}

Avila, L. A., and R. J. Pasch, 1992: Atlantic tropical systems of 1991. Mon. Wea. Rev., 120, 2688-2696.

Davey, M. K., and Coauthors, 2002: STOIC: A study of coupled model climatology and variability in tropical ocean regions. Climate Dyn., 18, 403-420.

Folland, C. K., T. N. Palmer, and D. E. Parker, 1986: Sahel rainfall and worldwide sea temperature 1901-1985. Nature, 320, 602-607.

Fontaine, B., and S. Janicot, 1996: Sea surface temperature fields associated with West African rainfall anomaly types. J. Climate, 9, 2935-2940.

Koster, R. D., and Coauthors, 2004: Regions of strong coupling between soil moisture and precipitation. Science, 305, 1138-1140.

Lamb, P. J., 1983: West African water variations between recent contrasting Subsaharan droughts. Tellus, 35A, $198-212$.

Landsea, C. W., and W. M. Gray, 1992: The strong association between Western Sahel monsoon rainfall and intense Atlantic hurricanes. J. Climate, 5, 435-453.

Le Barbé, L., T. Lebel, and D. Tapsoba, 2002: Rainfall variability in West Africa during the years 1950-90. J. Climate, 15, 187-202.

Nicholson, S. E., 1981: The nature of rainfall fluctuations in subtropical West Africa. Mon. Wea. Rev., 108, 473-487.

Parker, D. J., R. Burton, A. Diongue, R. J. Ellis, M. Felton, C. M. Taylor, C. D. Thorncroft, and P. Bessemoulin, 2005: The diurnal cycle of the west African monsoon circulation. Quart. J. Roy. Meteor. Soc., 131, 2839-2860.

Redelsperger, J. L., A. Diongue, A. Diedhiou, J. P. Ceron, M. Diop, J. F. Gueremy, and J. P. Lafore, 2002: Multiscale description of a Sahelian synoptic weather system representative of the West African monsoon. Quart. J. Roy. Meteor. Soc., 128, 1229-1257.

WCRP, 2000: CLIVAR Africa implementation plan. Informal Rep. 5/2000, ICPO Publication Series 35, 35 pp. [Available online at www.clivar.org/ organization/vacs/clivar_africa_iplan.htm.] 